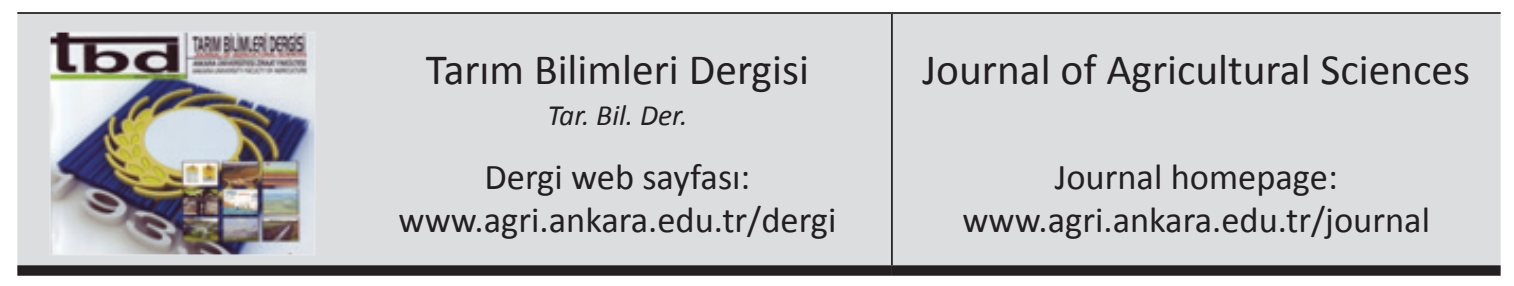

\title{
Beyşehir Gölü'ndeki Sudak (Stizostedion lucioperca, Linnaeus 1758) Balığı Kasında Bazı Ağır Metallerin Birikiminin Araştırılması
}

\author{
Emre ÇAĞLAK ${ }^{a}$, Barış KARSLI ${ }^{\mathrm{a}}$ \\ ${ }^{a}$ Recep Tayyip Erdoğan Üniversitesi, Su Ürünleri Fakültesi, İsleme Teknolojisi Anabilim Dall, Rize, TÜRKIYYE \\ ESER BILLISII \\ Araştırma Makalesi \\ Sorumlu Yazar: Emre ÇAĞLAK, E-posta: caglakemre@gmail.com,Tel: +90 (464) 2233385 \\ Geliş Tarihi: 01 Ağustos 2013, Düzeltmelerin Gelişi: 04 Kasım 2013, Kabul: 03 Ocak 2014
}

\section{ÖZET}

Bu çalışma; Türkiye'nin 3. büyük gölü olan Beyşehir Gölü’nden avlanan, tüketimi ve ihracatı yapılan sudak balığının mevsimsel olarak bazı ağır metal konsantrasyonlarını tespit etmek amacıyla yapılmıştır. Bu maksatla, sudak balıkları 20112012 yıllarında mevsimsel olarak bölge balıkçılarından temin edilmiştir. Sudak örneklerinin ağır metal analizleri indüktif çiftleşmiş olarak plazma/optik emisyon spektroskopisi (ICP-OES) cihazı kullanılarak yapılmıştır. Çalışma sonucunda, sudak kasındaki ağır metal içeriklerinin minimum ve maksimum değerleri; $\mathrm{Cd}, 0.008-0.047 \mathrm{mg} \mathrm{kg}^{-1}$; Co, 0.033-0.226 mg $\mathrm{kg}^{-1}$; Pb, 0.024-0.368 mg kg-1; Ni, 0.14-0.222 mg kg-1; Cr, 0.14-0.301 mg kg-1; Cu, 0.326-0.552 mg kg-1 ; Fe, 2.784-4.72 $\mathrm{mg} \mathrm{kg}{ }^{-1}$; Al, 5.449-8.859 mg kg-1; Zn, 15.85-26.497 $\mathrm{mg} \mathrm{kg}^{-1}$; Mn, 0.215-0.311 $\mathrm{mg} \mathrm{kg}^{-1}$ olarak tespit edilmiştir. Elde edilen sonuçlar ulusal sınır değerler ve uluslararası tüketilebilir ve standart değerler açısından karşılaştırılmıştır.

Anahtar Kelimeler: Sudak; Ağır metal; Beyşehir Gölü; Mevsimsel

\section{Investigation of Some Heavy Metals Accumulation in Muscle of Pike Perch (Stizostedion lucioperca, Linnaeus 1758) from Lake Beyşehir, Turkey}

\author{
ARTICLE INFO \\ Research Article \\ Corresponding Author: Emre ÇAĞLAK, E-mail: caglakemre@gmail.com, Tel: +90 (464) 2233385 \\ Received: 01 August 2013, Received in Revised Form:04 November 2013, Accepted: 03 January 2014
}

\begin{abstract}
This study was carried out in order to determine seasonally some heavy concentrations in pike perch (Stizostedion lucioperca) that is fished in Lake Beyşehir, which is the third biggest lake of Turkey, consumed and exported. For this purpose, pikeperch seasonally obtained from fishermen in the region in 2011-2012. Heavy metal analyzes of pikeperch were carried out by using inductively coupled plasma optical emission spectrometry (ICP-OES). At the end of the study, minimum and maximum heavy metal concentrations in muscle of pike perch were detected as $0.008-0.047 \mathrm{mg} \mathrm{kg}^{-1}$ for Cd, 0.033-0.226 mg kg-1 for Co, 0.024-0.368 $\mathrm{mg} \mathrm{kg}^{-1}$ for $\mathrm{Pb}, 0.14-0.222 \mathrm{mg} \mathrm{kg}^{-1}$ for Ni, $0.14-0.301 \mathrm{mg} \mathrm{kg}^{-1}$ for $\mathrm{Cr}, 0.326-0.552 \mathrm{mg} \mathrm{kg}^{-1}$ for Cu, 2.784-4.72 mg $\mathrm{kg}^{-1}$ for Fe, $5.449-8.859 \mathrm{mg} \mathrm{kg}^{-1}$ for Al, $15.85-26.497 \mathrm{mg} \mathrm{kg}^{-1}$ for $\mathrm{Zn}, 0.215-0.311 \mathrm{mg} \mathrm{kg}^{-1}$ for Mn. The obtained results were compared in terms of national limit values and international consumed and standart values.
\end{abstract}

Keywords: Pike perch; Heavy metal; Beyşehir Lake; Seasonal 


\section{Giriş}

Göl ekosistemleri, çeşitli antropojenik etkiler, ötrofikasyona neden olan besinlerin aşırı artması, endüstriyel, zirai ve evsel kökenli toksik kirlilik, su toplama alanı ve atmosfer yoluyla göllere ulaşan 1S1 kirliliği gibi etmenlerden sürekli etkilenmektedir. İnsan faaliyetlerinin tipik sonucu olarak tatlı sularda mevcut ağır metal düzeylerinin arttı̆̆1 kanıtlanmıştır (Atici et al 2010). Sucul organizmalarda ortalama ağır metal düzeylerinin tahmini ve standardize edilmesi oldukça zordur. Çünkü bunlar tür, cinsiyet, biyolojik döngü, balık büyüklüğ̈ gibi faktörler ile mevsim, bulundukları ortam, beslenme durumu, suyun sicaklığı ve tuzluluğu gibi ekolojik faktörlere bağlıdır (Ersoy 2006). Antropojenik aktivitelerin olumsuz etkilerinin besin zincirindeki organizmaların farklı halkalarında farklı etki gösterdiği bilinmektedir. Sudaki ağır metallerin önemli bir kısmının askıda partikül halde ve sedimentte yoğunlaştığ 1 bilinmektedir (Kayhan 2006; Koçbaş 2005). Özellikle iç sularda derişime bağlı olarak metal miktarları denizel ortamlara kıyasla daha yüksek seviyelere ulaşabilmektedir. Ayrıca mevsimsel yönden iç su miktarlarındaki azalma ve artışlar büyük farkl1lıklar göstermektedir. Bu farklılıklar ortamdaki metal yoğunluğunu ve balıklarda metal birikimini etkilemektedir. Balık bünyesindeki ağır metaller deri, solungaçlar ve boşaltım yoluyla atılabileceği gibi, belirli bir dokuda da depolanabilirler (Uysal \& Atalay 2007).

Biyolojik sistemlerde önemli bir role sahip olan demir, çinko, bakır gibi bazı metaller esansiyel olup, kadmiyum, kurşun gibi eser miktarda bile toksik olan bazı metaller ise esansiyel değildir. Mineraller ve iz elementler beslenmede çok önemli bileşenlerdir. Eksiklikleri ya da fazla miktarda bulunmaları insanlarda ciddi sağlık problemlerine neden olabilir. İz elementlerin eksikliği özellikle bebeklerin ve çocukların büyüme ve gelişme döneminde önemli etkiler yapmaktadır (Özden et al 2010). İnsan sağlığına çeşitli zararları olan kadmiyum, kurşun gibi bazı metallerin yanı sıra faydalı olanları da vardır. Örneğin, kobalt B12 vitaminin bir parçasıdır, demir vücutta birçok hayati fonksiyona sahiptir, çinko birçok enzimin sentezinde ve indirgenmesinde, karbonhidratların, yağların, proteinlerin ve nükleik asitlerin indirgenmesinde ayrıca mikro besinlerin metabolizmasında bulunan önemli bir bileşiktir (Alina et al 2012; ATSDR 2004; Mol 2011; ATSDR 2013; Pazi 2011; Nisbet et al 2010; Özden et al 2010; Özparlak et al 2012).

Türkiye'nin en büyük tatlı su gölü olan Beyşehir Gölü, "A" grubu sulak alan ve SíT alanı kapsamı altındadır. Göl birinci derece içme suyu kıstasına uyması nedeniyle İçme ve Kullanma Suyu Koruma Sahası statüsüne sahiptir (Fakığlu \& Demir 2011).

Beyşehir Gölü kirlilik açısından değerlendirildiğinde "Beyşehir Gölü’nün Sorunları ve Alınması Gereken Önlemler" başlıklı raporda gölün kirliliğinin önemli düzeylere ulaştığ belirtilmiştir. $\mathrm{Bu}$ rapora göre göldeki kirliğin tarımsal, sanayileşme, evsel atıklar vb. nedenlerden kaynaklandığı ifade edilmiştir (Babaoğlu 2007). Ayrıca yapılan çeşitli çalışmalar, su ürünlerinde ve sedimentte ağır metal birikiminin yüksek seviyelere ulaştığını belirtmektedir (Özparlak et al 2012; Atıcı et al 2010). Beyşehir Gölü'nde yıl içinde su sicaklığ 1 değerlerinin $20.9-0.7{ }^{\circ} \mathrm{C}$ (Sarı \& İnan 2011), çözünmüş oksijen değerlerinin $11.8-8 \mathrm{mg}$ $\mathrm{L}^{-1}, \mathrm{pH}$ değerlerinin ise 7.8-8.2 arasında (Altındağ \& Yiğit 2004) değiştiği bildirilmiştir.

Ekonomik bir tür olan sudak (Stizostedion lucioperca, L., 1785) Beyşehir Gölü’ne 1978 yılında aşılanmıştır (Tümgelir et al 2007). Bölgedeki su ürünleri işleme tesisleri sudak ve diğer balık türlerinin işlenmesinde faaliyet göstermektedir (Babaoğlu 2007). Bir çalışmada kadife balığının Göller Bölgesi'nde ve çoğu Beyşehir Gölü civarında yer alan 20 kadar tesiste fileto halinde işlendiği bildirilmiştir (Anonim 2003; Zencir \& Korkmaz 2004). Sudak'ın ülkemizde 2010-2012 yılları arasında toplam avc1lığ 2806.2 ton olarak gerçekleşmiş ve 2012 yılındaki toplam parasal değeri 3.830.780 TL olarak bildirilmiştir (TUİK 2012).

$\mathrm{Bu}$ çalışmada tüketimi yapılan sudakın kas yapısında bulunan bazı ağır metallerin $(\mathrm{Cd}, \mathrm{Co}, \mathrm{Pb}$, 
$\mathrm{Ni}, \mathrm{Cr}, \mathrm{Cu}, \mathrm{Fe}, \mathrm{Al}, \mathrm{Zn}, \mathrm{Mn}$ ) mevsimsel değişimlerinin tespit edilmesi ve elde edilen sonuçların ulusal/ uluslararası standart değerler ve uluslararası tüketilebilir sınır değerler ile karşılaştırılarak balığın tüketilebilirlik durumu ortaya konmuştur.

\section{Materyal ve Metot}

\section{1.Çalışma bölgesi ve süresi}

Bu çalışma 2011-2012 yıllarında mevsimsel olarak, Konya ve Isparta ili sınırları içerisinde $37^{\circ} 47^{\prime} 0^{\prime \prime} \mathrm{K}$, $31^{\circ} 33^{\prime} 0^{\prime \prime} \mathrm{D}$ koordinatlarında yer alan Beyşehir Gölü'nde yürütülmüştür. Ortalama yüzölçümü 650 $\mathrm{km}^{2}$ olan Beyşehir Gölü’nün, ortalama derinliği $8.5 \mathrm{~m}$ ve deniz seviyesinden yüksekliği $1115 \mathrm{~m}$ civarındadır (Babaoğlu 2007) (Şekil 1).

\subsection{Ballk materyali}

Sudak, gölün Beyşehir ilçesi sınırlarında uzatma ağlarıyla avlanan balıkçılardan temin edilmiştir. Ortalama boyları $34.91 \pm 0.64 \mathrm{~cm}$ ve ortalama ağırlıkları $413.89 \pm 33.5 \mathrm{~g}$ olan 2-3 yaş aralığında toplam 80 adet balık çalışma materyali olarak kullanılmıştır. Sudakların boy ve ağırlık ölçümleri $0.1 \mathrm{~mm}$ hassasiyetli dijital kumpas (Mahr 16ER) ve $0.01 \mathrm{gr}$ hassasiyetli elektronik terazi (And GR-200) ile yapılmıştır. Analiz işlemleri öncesinde balıklar $-70{ }^{\circ} \mathrm{C}^{\prime}$ de muhafaza edilmiştir.

\subsection{Ağır metal analizi}

Balık kası örnekleri $105{ }^{\circ} \mathrm{C}$ 'de kurutulmuş ve porselen havanda ezilerek homojenize olmas1 sağlanmıştır. Karışımdan alınan 0.5 gr örnek $5 \mathrm{ml}$

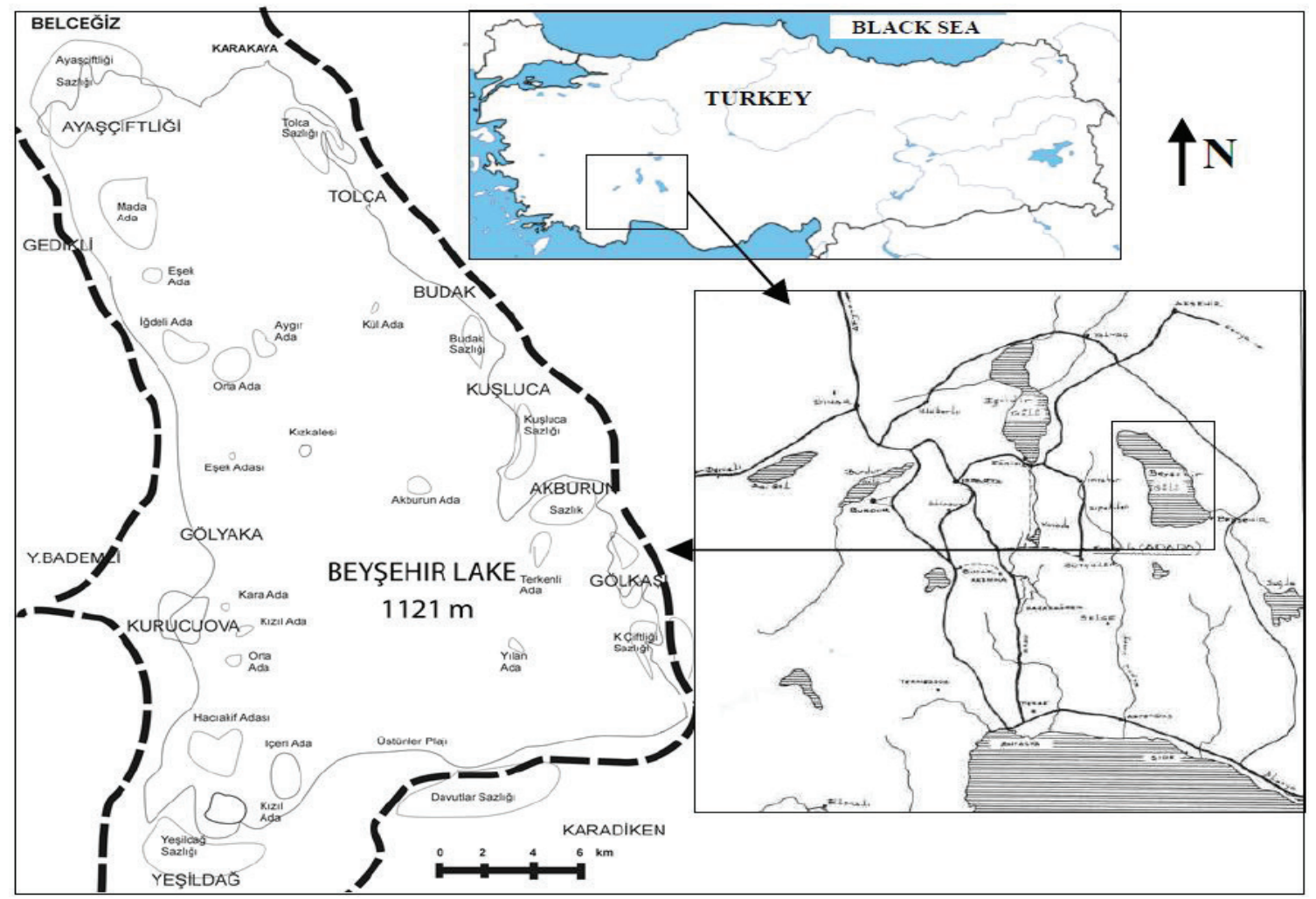

Şekil 1- Beyşehir Gölü Haritası (Özparlak et al 2012)

Figure 1- The map of Lake Beyşehir (Özparlak et al 2012) 
(\% 65'lik) nitrik asitte 24 saat oda sicaklığında bekletilmiştir. Bekletme işleminden sonra 100 ${ }^{\circ} \mathrm{C}$ 'de 4 saat asitle yakma işlemi yapılmıştır. Yakılmış ürünler oda sıcaklığında soğutulmuş ve filtre edilerek süzülmüştür (Whatman No:42). Süzülen örnekler deiyonize su ile 25 ml'ye tamamlanmıştır. Kadmiyum (Cd), kobalt (Co), kurşun $(\mathrm{Pb})$, nikel $(\mathrm{Ni})$, krom $(\mathrm{Cr})$, bakır $(\mathrm{Cu})$, demir ( $\mathrm{Fe})$, alüminyum ( $\mathrm{Al})$, çinko $(\mathrm{Zn})$ ve mangan $(\mathrm{Mn})$ değerlerinin belirlenmesinde Inductive Coupled Plasma Optic Spectrometer (ICP-OES) kullanılmıştır. Bütün örneklerin analize hazırlanma işlemleri FAO Teknik Rapor 158'e göre yapılmıştır (Bernhard 1976, Zhang et al 2007, Sukender et al 2012).

Uluslararası kuruluşlar tarafindan bazı ağır metallerin insanlar tarafından 1 günlük kilogram başına $\left(\mathrm{mg} \mathrm{kg}^{-1} \mathrm{day}^{-1}\right)$ ve günlük tüketime izin verilen değerleri $\left(\mathrm{mg} \mathrm{day}^{-1}\right)$ Çizelge 1 'de gösterilmektedir. Kilogram başına tüketime izin verilen değerler insan vücut ağırlığı ile çarpılarak hesaplanmaktadır (genelde 60-70 kg'lık insanların vücut ağırlıkları dikkate alınmaktadır). Çalışmamızda $70 \quad \mathrm{~kg}$ ağırlık dikkate alınarak tüketim yönünden değerlendirmelerde bulunulmuştur (Örnek; Co için; 70x0.01=0.7 mg day $\left.{ }^{-1}\right)($ ATSDR 2004;2013, Özparlak at al 2012). Ulusal ve uluslararas1 referanslarda su ürünlerinde ağır metal sınır değerleri yaş ağırlık üzerinden verilmektedir. Bu kapsamda çalışmamızda kuru ağırlık üzerinden yapılan ağır metal analiz konsantrasyonları hesaplanarak yaş ağırlık biriminde ifade edilmiştir (Çizelge 2).

\subsection{Istatistik analizi}

İstatistiki analizde SPSS 11.0 (SPSS, Inc., Chicago, IL, USA) paket programı kullanılmıştır. Elde edilen verilerin farkların saptamak amacı ile varyansları homojen bulunan gruplara önemlilik testi uygulanmıştır. $\mathrm{Bu}$ önemlilik testi için 'One Way Anova' ve en küçük önemli fark 'LSD' uygulanmış, önem derecesi $\mathrm{P}<0.05$ şeklinde kullanılmıştır (Sümbüloğlu \& Sümbüloğlu 2000).

\section{Bulgular ve Tartışma}

Sudak kasının Cd, Co, Pb, Ni, Cr, Cu, Fe, Al, Zn ve Mn miktarları mevsimsel olarak Çizelge 3 ve Şekil 2'de mg kg-1 yaş ağırlık üzerinden gösterilmiştir. $\mathrm{Cd}$ miktarının en yüksek değeri sonbaharda $0.047 \pm 0.007 \mathrm{mg} \mathrm{kg}^{-1}$, en düşük değeri ise ilkbaharda $0.008 \pm 0.000 \mathrm{mg} \mathrm{kg}^{-1}$ olarak ölçülmüştür. Sudak kas1 içerisindeki $\mathrm{Cd}$ miktarının mevsimlere göre en yüksek değerden en düşük değere göre sıralaması sonbahar, yaz, kış ve ilkbahar olmuştur. İlkbaharda $\mathrm{Cd}$ miktarının diğer mevsimlerden önemli oranda düşük bulunması istatistiki açıdan da farklılığını ortaya koymaktadır $(\mathrm{p}<0.05)$.

İlkbahar, yaz, sonbahar ve kış mevsimsel dönemlerinde Co miktarı sırasıyla $0.226 \pm 0.12 \mathrm{mg} \mathrm{kg}^{-1}$,

Çizelge 1- Uluslararası standartlarda bazı ağır metallerin tüketilebilir sınır değerleri (mg $\mathbf{~ k g ~}^{-1}$ yaş ağırlık)

Table 1- Consumable limit values of certain heavy metals in International standards limit values $\left(\mathrm{mg} \mathrm{kg}^{-1}\right.$ wet weight)

\begin{tabular}{|c|c|c|c|c|c|c|c|c|c|}
\hline & $C d$ & Co & $\mathrm{Pb}$ & $\mathrm{Cr}$ & $\mathrm{Cu}$ & $\mathrm{Fe}$ & $A l$ & $Z n$ & $M n$ \\
\hline ATSDR (MRLs) (2004;2013) & 0.0003 & 0.01 & \multirow{2}{*}{ - } & 0.005 & 0.01 & \multirow{2}{*}{ - } & 1.0 & 0.3 & \multirow{2}{*}{-} \\
\hline Or $=$ Oral $\left(\mathrm{mg} \mathrm{kg}^{-1}\right.$ day $\left.^{-1}\right)$ & Or. & Or. & & Or. & Or. & & Or. & Or. & \\
\hline EPA $2000\left(\mathrm{mg} \mathrm{kg}^{-1}\right.$ day $\left.^{-1}\right)$ & 0.001 & - & - & - & - & - & - & - & - \\
\hline $\begin{array}{l}\text { Çin Besin Enstitüsü }\left(\mathrm{mg} \mathrm{day}^{-1}\right) \\
\text { Chen et al (2007) }\end{array}$ & - & - & - & - & 1.0 & 12 & - & 12 & 3.5 \\
\hline \multicolumn{10}{|l|}{ FAO/WHO $\left(\mathrm{mg} \mathrm{kg}^{-1} \mathrm{day}^{-1}\right)$} \\
\hline Codex Standard 193 (1995) & 0.001 & - & 0.0035 & - & 0.5 & - & 1.0 & 1.0 & - \\
\hline Figueira et al (2011) & & & & & & & & & \\
\hline
\end{tabular}


Çizelge 2- Ulusal ve uluslararası standartlarda balık kasında bazı ağır metallerin sınır değerleri (mg $\mathbf{~ k g}^{-1}$ yaş ağırlık)

Table 2- Limit values of certain heavy metals in fish muscle in National and International standards ( $\mathrm{mg} \mathrm{kg}^{-1}$ wet weight)

\begin{tabular}{|c|c|c|c|c|c|c|c|c|c|c|}
\hline & $C d$ & $\mathrm{Co}$ & $\mathrm{Pb}$ & $N i$ & $\mathrm{Cr}$ & $\mathrm{Cu}$ & $\mathrm{Fe}$ & $A l$ & $Z n$ & $M n$ \\
\hline $\begin{array}{l}\text { TKB. KKGM. Su } \\
\text { Ürünleri Kalite Kontrol } \\
\text { El Kitab1 (2000) }\end{array}$ & $0.05-0.1$ & - & 1.0 & - & - & 20 & - & - & 50 & - \\
\hline $\begin{array}{l}\text { Türk G1da Kodeksi } \\
(2002)\end{array}$ & $0.05-0.1$ & - & $0.2-0.4$ & - & - & 20 & - & - & 50 & - \\
\hline $\begin{array}{l}\text { Türk Gıda Kodeksi } \\
\text { (2011) }\end{array}$ & $0.05-0.3$ & - & 0.3 & - & - & - & - & - & - & - \\
\hline $\begin{array}{l}\text { Codex Standard } \\
193(1995)\end{array}$ & - & - & 0.3 & - & - & - & - & - & - & - \\
\hline $\mathrm{EC} \mathrm{(2001)}$ & $0.05-0.1$ & - & $0.2-0.4$ & - & - & - & - & - & - & - \\
\hline EC (2008) & $0.05-0.3$ & - & 0.3 & - & - & - & - & - & - & - \\
\hline IAEA ( 2003) & 0.189 & 0.1 & 0.12 & 0.6 & 0.73 & 3.28 & 146 & 13.8 & 67.1 & 3.52 \\
\hline $\begin{array}{l}\text { FAO / WHO (1989) } \\
\text { Özparlak et al (2012) }\end{array}$ & 0.5 & - & 0.5 & - & - & 30 & - & - & 40 & - \\
\hline $\begin{array}{l}\text { Çin Gida Standard } \\
\text { (1999) }\end{array}$ & & & & & & & & & & \\
\hline $\begin{array}{l}\text { Zhang et al (2007) } \\
\text { Pan and Wang (2012) } \\
\text { Özparlak et al (2012) }\end{array}$ & - & - & $0.5-1.0$ & - & $2<$ & $10-50$ & - & - & 50 & - \\
\hline $\begin{array}{l}\text { Uluslararası Bazı Değer } \\
\text { Aralıkları } \\
\text { Özparlak et al (2012) }\end{array}$ & $0.0-2$ & - & $0.5-10$ & - & - & $10-100$ & - & - & $40-100$ & - \\
\hline
\end{tabular}

\section{Çizelge 3- Sudak kasında ağır metal miktarları (mg kg-1 yaş ağırlık)}

Table 3- Heavy metals amount in muscle of pike perch ( $\mathrm{mg} \mathrm{kg}^{-1}$ wet weight)

\begin{tabular}{cllll}
\hline \multirow{2}{*}{$\begin{array}{c}\text { ğ } 1 \mathrm{r} \text { metaller } \\
\left(m g ~ k g^{-1}\right)\end{array}$} & \multicolumn{3}{c}{ Sudak mevsimsel dönemler } \\
\cline { 2 - 5 } İlkbahar & Yaz & Sonbahar & K1ş \\
\hline $\mathrm{Cd}$ & $0.008 \pm 0.000^{\mathrm{c}}$ & $0.038 \pm 0.000^{\mathrm{ab}}$ & $0.047 \pm 0.007^{\mathrm{a}}$ & $0.03 \pm 0.000^{\mathrm{b}}$ \\
$\mathrm{Pb}$ & $0.226 \pm 0.12^{\mathrm{a}}$ & $0.033 \pm 0.006^{\mathrm{b}}$ & $0.047 \pm 0.007^{\mathrm{b}}$ & $0.045 \pm 0.007^{\mathrm{b}}$ \\
$\mathrm{Ni}$ & $0.368 \pm 0.106^{\mathrm{a}}$ & $0.024 \pm 0.006^{\mathrm{c}}$ & $0.217 \pm 0.067^{\mathrm{ab}}$ & $0.15 \pm 0.000^{\mathrm{b}}$ \\
$\mathrm{Cr}$ & $0.222 \pm 0.006^{\mathrm{a}}$ & $0.14 \pm 0.006^{\mathrm{b}}$ & $0.164 \pm 0.007^{\mathrm{b}}$ & $0.159 \pm 0.000^{\mathrm{b}}$ \\
$\mathrm{Cu}$ & $0.207 \pm 0.000^{\mathrm{b}}$ & $0.14 \pm 0.006^{\mathrm{c}}$ & $0.196 \pm 0.007^{\mathrm{b}}$ & $0.301 \pm 0.14^{\mathrm{a}}$ \\
$\mathrm{Fe}$ & $0.552 \pm 0.006^{\mathrm{a}}$ & $0.411 \pm 0.006^{\mathrm{b}}$ & $0.371 \pm 0.000^{\mathrm{c}}$ & $0.326 \pm 0.007^{\mathrm{d}}$ \\
$\mathrm{Al}$ & $4.72 \pm 0.046^{\mathrm{a}}$ & $3.173 \pm 0.013^{\mathrm{b}}$ & $4.625 \pm 0.067^{\mathrm{a}}$ & $2.784 \pm 0.063^{\mathrm{c}}$ \\
$\mathrm{Zn}$ & $8.859 \pm 0.046^{\mathrm{a}}$ & $7.401 \pm 0.109^{\mathrm{b}}$ & $5.910 \pm 0.112^{\mathrm{c}}$ & $5.449 \pm 0.539^{\mathrm{c}}$ \\
$\mathrm{Mn}$ & $26.497 \pm 0.093^{\mathrm{a}}$ & $18.014 \pm 0.424^{\mathrm{b}}$ & $15.85 \pm 0.142^{\mathrm{c}}$ & $18.308 \pm 0.73^{\mathrm{b}}$
\end{tabular}

a ve $b$ harflerini taşıyan gruplar arasındaki farklılık istatistiki olarak önemlidir $(\mathrm{p}<0.05)$ 
$0.033 \pm 0.006 \mathrm{mg} \mathrm{kg}{ }^{-1}, 0.047 \pm 0.007 \mathrm{mg} \mathrm{kg}^{-1}$ ve $0.045 \pm 0.007 \mathrm{mg} \mathrm{kg}{ }^{-1}$ olarak tespit edilmiştir. Görüldüğü gibi en üst değer ilkbahar mevsiminde, en düşük değer yaz mevsiminde bulunmuştur. Yapılan değerlendirmede ilkbahardaki Co miktarı diğer mevsimlerden önemli oranda farkl1lık göstermiştir $(\mathrm{p}<0.05)$.

Mevsimsel olarak $\mathrm{Pb}$ miktarının dağılımı; ilkbahar mevsiminde $0.368 \pm 0.106 \mathrm{mg} \mathrm{kg}^{-1}$, yaz mevsiminde $0.024 \pm 0.006 \mathrm{mg} \mathrm{kg}^{-1}$, sonbahar mevsiminde $0.217 \pm 0.067 \mathrm{mg} \mathrm{kg}^{-1}$ ve kış mevsiminde $0.15 \pm 0.000 \mathrm{mg} \mathrm{kg}{ }^{-1}$ şeklinde gerçekleşmiştir. İlkbahar ve sonbahar mevsiminde yüksek seviyelere ulaşan $\mathrm{Pb}$ miktarları arasında bir fark görülmemiştir (p>0.05). Yaz mevsiminde balık kasında düşüş gösteren $\mathrm{Pb}$ miktarı diğer gruplardan önemli derecede farklılık göstermiştir $(\mathrm{p}<0.05)$.

$\mathrm{Ni}$ miktarı yönünden yapılan incelemede en yüksek değer ilkbahar mevsiminde $(0.222 \pm 0.006$ $\left.\mathrm{mg} \mathrm{kg}^{-1}\right)$, en düşük değer $\left(0.14 \pm 0.006 \mathrm{mg} \mathrm{kg}^{-1}\right)$ yaz mevsiminde belirlenmiştir. İlkbahar mevsimi $\mathrm{Ni}$ miktarının diğer mevsimlerden yüksek ölçülmesi diğer gruplardan farklılığını ortaya koymuştur $(p<0.05)$. Yaz, sonbahar ve kış mevsiminde Ni miktarı yönünden birbirleri üzerinde bir fark oluşturacak değer bulunmamıştır ( $p>0.05$ ).

Balıklarda $\mathrm{Cr}$ miktarı en küçük değerden büyüğe doğru sirasıyla yaz mevsiminde $0.14 \pm 0.006$ mg kg-1, sonbahar mevsiminde $0.196 \pm 0.007$ $\mathrm{mg} \mathrm{kg}{ }^{-1}$, ilkbahar mevsiminde $0.207 \pm 0.000 \mathrm{mg}$ $\mathrm{kg}^{-1}$, kış mevsiminde $0.301 \pm 0.14 \mathrm{mg} \mathrm{kg}^{-1}$ olmuştur. Kış mevsiminde balık kasındaki Cr miktarı en üst seviyeye ulaşmış ve diğer mevsimlere göre önemli bir farklılık göstermiştir $(\mathrm{p}<0.05)$.

Kas içerisindeki $\mathrm{Cu}$ değerleri ilkbahar mevsiminde $0.552 \pm 0.006 \mathrm{mg} \mathrm{kg}^{-1}$, yaz mevsiminde $0.411 \pm 0.006 \mathrm{mg} \mathrm{kg} \mathrm{kg}^{-1}$, sonbahar mevsiminde $0.371 \pm 0.000 \mathrm{mg} \mathrm{kg}^{-1}$ ve $\mathrm{k}$ ı̧̧ mevsiminde $0.326 \pm 0.007 \mathrm{mg} \mathrm{kg}^{-1}$ olarak belirlenmiştir. Şekil 2'de görüldüğü gibi $\mathrm{Cu}$ miktarı ilkbahar mevsiminden itibaren düzenli bir azalış göstermiştir. Bütün mevsimler arasındaki farklılık bu düzenli azalıştan kaynaklanmaktadır ve önemli bir fark olarak tespit edilmiştir $(\mathrm{p}<0.05)$.
Mevsimsel olarak Fe miktarı $2.784 \pm 0.063 \mathrm{mg}$ $\mathrm{kg}^{-1}\left(\mathrm{k}\right.$ ş) ile $4.72 \pm 0.046 \mathrm{mg} \mathrm{kg}^{-1}$ (İlkbahar) değerleri arasında dağılım göstermiş̧tir. Fe miktarının ilkbahar ve sonbahar mevsimlerinde yükselişte olduğu Şekil 2'de görülmektedir. Her iki mevsimde diğer gruplardan önemli oranda farklılık göstermiştir $(\mathrm{p}<0.05)$.

İlkbahar mevsiminde $8.859 \pm 0.046 \mathrm{mg} \mathrm{kg}^{-1}$ ile en yüksek seviyeye ulaşan $\mathrm{Al}$ değeri, kış mevsiminde $5.449 \pm 0.539 \mathrm{mg} \mathrm{kg}^{-1}$ 'a en düşük seviyeye inmiştir (Şekil 2). İlkbahar mevsimi ile diğer mevsimlerin Al miktarları arasındaki fark önemli bulunmuştur $(\mathrm{p}<0.05)$.

Sudak kasında Zn miktarı ilkbahar mevsiminde $26.497 \pm 0.093 \mathrm{mg} \mathrm{kg}{ }^{-1}$ ile en yüksek değerine ulaşmıştır. Yaz ve sonbahar mevsimlerinde sırasıyla $18.014 \pm 0.424 \mathrm{mg} \mathrm{kg}{ }^{-1}, 15.850 \pm 0.142 \mathrm{mg} \mathrm{kg}^{-1}$ değerleri ölçülmüştür. Kış mevsiminde yükselme eğilimi göstererek $18.308 \pm 0.73 \mathrm{mg} \mathrm{kg}^{-1}$ seviyesine ulaşmıştır. Yapılan istatistiki değerlendirmede yaz ve kış mevsimlerinde bir fark görülmemiş ( $p>0.05$ ), diğer mevsimler arasındaki farklılık önemli bulunmuştur $(\mathrm{p}<0.05)$.

Mn değerleri ilkbahar mevsiminde $0.311 \pm 0.000$ $\mathrm{mg} \mathrm{kg}{ }^{-1}$, yaz mevsiminde $0.217 \pm 0.006 \mathrm{mg} \mathrm{kg}^{-1}$, sonbahar mevsiminde $0.233 \pm 0.000 \mathrm{mg} \mathrm{kg}{ }^{-1}$ ve kış mevsiminde $0.215 \pm 0.007 \mathrm{mg} \mathrm{kg} \mathrm{kg}^{-1}$ olarak belirlenmiştir. İlkbahar mevsimi Mn değeri diğer gruplardan yüksek olması ile farklılık göstermiştir $(p<0.05)$. Diğer mevsimler arasında Mn değerleri yönünden istatistiki bir fark görülmemiştir ( $p>0.05)$.

\section{Sonuçlar}

Su ürünlerinde özellikle balık kasında, insan sağlığı dikkate alınarak ağır metallerin sınır değerlerinin belirlenmesi noktasında önemli çalışmalar yapılmıştır. Yapılan çalışmalar neticesinde ulusal ve uluslararası veriler elde edilmiştir. Bölgesel olarak mineral maddelerin sınır değerlerinde farklılıklar gözlense de, dünya genelinde belirli bir standart oluşmaya başlamıştır (Çizelge 2). Türkiye iç suları balık türlerinde ağır metal içeriklerinin tespiti amacı ile yapılmış araştırmalar Çizelge 4'de gösterilmiştir. 

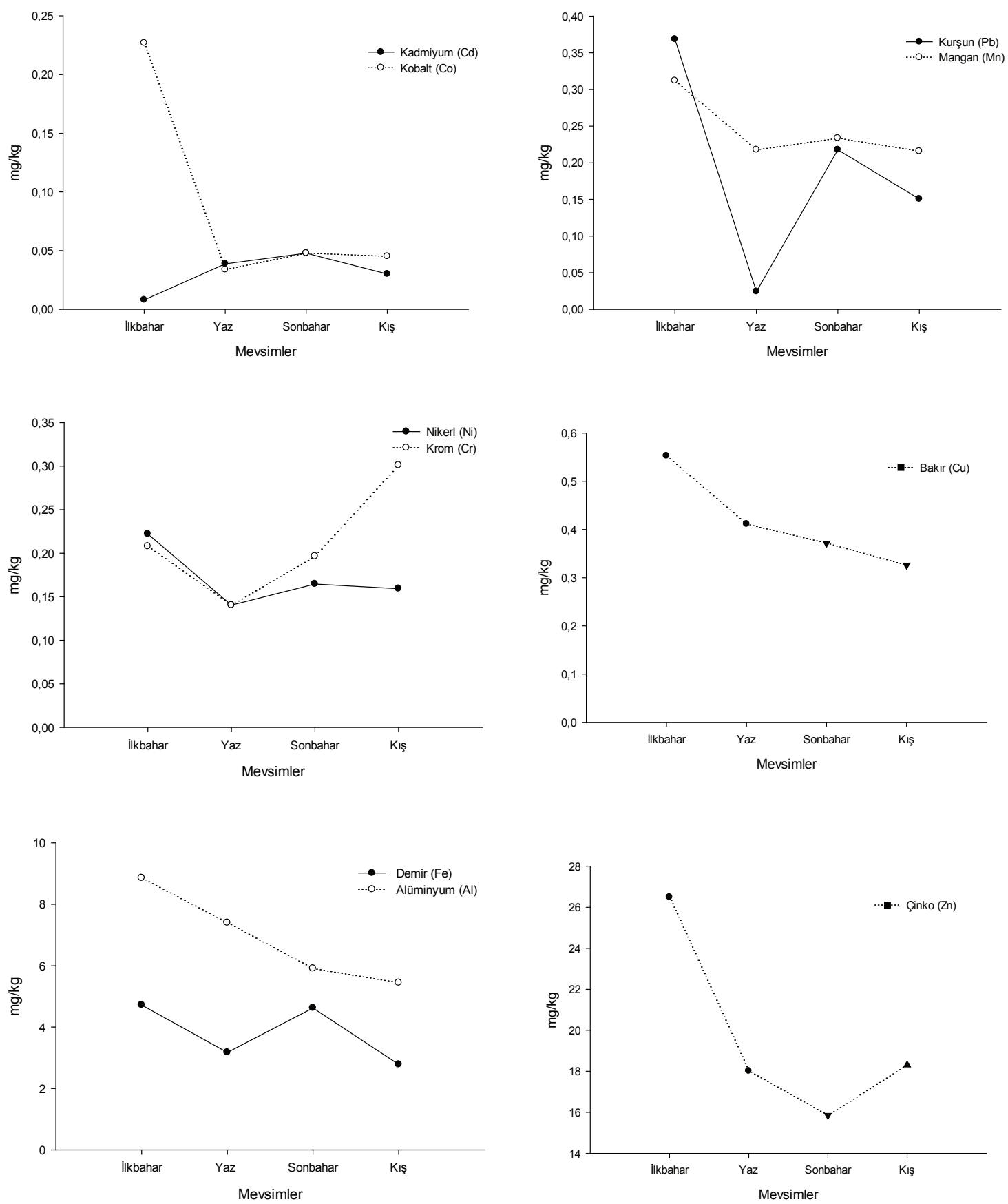

Şekil 2- Sudak kasında ağır metal miktarlarının mevsimsel dağılımları

Figure 2-Seasonal distribution of the heavy metals amount in muscle of pike perch 
Çalışmamızda Cd balık kasında en yüksek değer sonbahar mevsiminde $\left(0.047 \pm 0.007 \mathrm{mg} \mathrm{kg}^{-1}\right)$, en düşük değer ilkbahar mevsiminde $(0.008 \pm 0.000$ $\mathrm{mg} \mathrm{kg}^{-1}$ ) ölçülmüştür. Göksu et al (2003)'ın yaptığ1 araştırma sonuçları ile çalışma verilerimiz paralellik göstermektedir. Diğer çalışmaların Cd sonuçları bulgularımızdan yüksek bulunmuştur (Çizelge 4).

Araştırma materyalimizde Co miktarı 0.033$0.226 \mathrm{mg} \mathrm{kg}^{-1}$ değerleri arasında tespit edilmiştir. Uysal et al (2009) yaptığı çalışmada Co miktarını sınır değerlerinin altında bulmuştur. Özparlak et al (2012) yaptığı araştırmada sudak kasında Co miktarını 2.5-2.82 mg kg-1 olarak bulmuşlardır. Çalışmamızdan yüksek bulunan sonuçların bölge, zaman, örnek sayısı ve materyal (boyağırlık yönünden) farklılığından kaynaklandığı düşünülmektedir.

$\mathrm{Pb}$ miktarı yönünden yapılan çalışmalar incelendiğinde en düşük değerin $0.675 \mathrm{mg} \mathrm{kg}{ }^{-1}$ ile Altındağ \& Yiğit (2005) tarafından verildiği görülmektedir, diğer çalışma sonuçlarının tamamı bu değerin üzerinde bulunmuştur. Araştırma sonucunda elde ettiğimiz $\mathrm{Pb}$ değerleri 0.024$0.368 \mathrm{mg} \mathrm{kg}^{-1}$ arasında değişmektedir. Elde edilen sonuçların yapılan bütün çalışmalardan düşük olduğu gözlenmiştir.

Ni miktarı çalışma süresince en yüksek değerine ilkbahar mevsiminde $\left(0.222 \pm 0.006 \mathrm{mg} \mathrm{kg}^{-1}\right)$ ulaşmıştır. Yapılan çalışmalar ile karşılaştırıldığında Uysal et al (2009) tarafindan $\mathrm{Ni}$ değerleri tespit limitlerinin altında bulunurken, diğer araştırmacıların sonuçları 1-3.5 $\mathrm{mg} \mathrm{kg}^{-1}$ arasında değişiklik göstermiştir. Araştırma sonucunda ilkbahar mevsiminde elde ettiğimiz en yüksek değerin bile yapılan çalışmalardan oldukça düşük kaldığı gözlenmiştir (Çizelge 4).

Araştırmamız süresince elde edilen $\mathrm{Cr}$ değerlerinin dağılımı Çizelge 3'de verilmiştir. Literatür çalışmaları ile karşılaştırıldığında aynı tür ve aynı bölge üzerine çalışan Altındağ \& Yiğit (2005)'in elde ettiği sonuçlar (0.25-0.26 mg kg-1) ile araştırma sonuçlarımız benzerlik göstermektedir. Diğer araştırmacıların elde ettiği sonuçlar çalışma değerlerimizden yüksek bulunmuştur.
$\mathrm{Cu}$ sonuçları ilkbahar, yaz, sonbahar ve kış mevsimlerinde sirasiyla $0.552 \pm 0.006,0.411 \pm 0.006$, $0.371 \pm 0.000$ ve $0.326 \pm 0.007 \mathrm{mg} \mathrm{kg}^{-1}$ bulunmuştur. Özyurt et al (2009)'un yaptığı araştırmada elde ettiği $0.13 \mathrm{mg} \mathrm{kg}^{-1} \mathrm{Cu}$ sonucundan çalışma verilerimiz daha yüksek tespit edilmiştir. Uysal et al (2009)'un Carassius carassius türünde tespit ettikleri $\mathrm{Cu}$ miktarı $\left(0.39 \mathrm{mg} \mathrm{kg}^{-1}\right)$ ile araştırma sonuçlarımız benzerlik göstermektedir. Diğer araştırmacıların verileri ile karşılaştırıldığında elde ettiğimiz bakır değerlerinin düşük olduğu belirlenmiştir.

Çalışmamızda elde ettiğimiz Fe miktarları ile Çizelge 4'de verilen Özparlak et al (2012), TekinÖzan \& Kır (2008), Tekin-Özan (2008), Tekin-Özan \& Kır (2007a) ve Göksu et al (2003)'ın sonuçları ile paralellik göstermektedir.

İlkbahar mevsiminde sudak kasında 8.859 \pm 0.046 mg kg-1 olarak ölçülen Al miktarı yaz ve sonbahar mevsiminde düşüş göstermiştir. Kış mevsiminde düşüşe devam eden Al miktarı $5.449 \pm 0.539 \mathrm{mg}$ $\mathrm{kg}^{-1}$ değerini almıştır. Literatür araştırmalarında Al yönünden değerlendirme yapılacak kaynağa rastlanılmamıştır, bu yönüyle iç sular balık türleri ve sudak balığı için araştırma sonuçlarımızın bir kaynak oluşturabileceği kanaatine varılmıştır.

Mevsimsel olarak $\mathrm{Zn}$ miktarı yönünden araştırma sonuçlarımız 26.497 $\pm 0.093-15.850 \pm 0.142$ $\mathrm{mg} \mathrm{kg}^{-1}$ değerleri arasında bulunmuştur. Elde ettiğimiz sonuçların, Mendil et al (2005) ve Uysal et al (2009)'ın araştırma verileri ile karşılaştırıldığında benzerlik gösterdiği tespit edilmiştir. Ayrıca TekinÖzan \& Kır (2008)'ın yaptığı çalışma verileri elde ettiğimiz değerlere yakın bulunmuştur. Diğer literatür verilerinin araştırma sonuçlarımızdan düşük bulunduğu gözlenmiştir (Çizelge 4).

Mn değerleri yaptığımız çalışmada sudak kasında en düşük kış mevsiminde $0.215 \pm 0.007$ $\mathrm{mg} \mathrm{kg}^{-1}$, en yüksek ilkbahar mevsiminde $0.311 \pm$ $0.000 \mathrm{mg} \mathrm{kg}^{-1}$ olarak tespit edilmiştir. Çizelge 4'de yapılan çalışmalar ile karşılaştırıldığında araştırma sonuçlarımızın tüm çalışmalardan düşük olduğu bulunmuştur. Uysal et al (2009) ve Özyurt et al (2009)'un yaptıkları çalışmalarda elde ettikleri Mn 
Çizelge 4- Türkiye iç suları balık türlerinde ağır metal içerikleri üzerine yapılmış çalışmalar

Table 4- The conducted studies on the content of heavy metals in freshwater fish species of Turkey

\begin{tabular}{|c|c|c|c|c|c|c|c|c|c|}
\hline \multirow{2}{*}{$\begin{array}{c}\text { Araştırmact; Materyal; } \\
\text { Bölge ve zaman }\end{array}$} & \multicolumn{9}{|c|}{ Ağır metaller (minimum-maksimum) $m g \mathrm{~kg}^{-1}$} \\
\hline & $C d$ & Co & $P b$ & $\mathrm{Ni}$ & $\mathrm{Cr}$ & $\mathrm{Cu}$ & $\mathrm{Fe}$ & $Z n$ & $M n$ \\
\hline Özparlak et al (2012) (kuru ağırlık) & 2.0 & 2.5 & 1.03 & 1.01 & 12.02 & 1.32 & 1.49 & 7.0 & 9.0 \\
\hline $\begin{array}{l}\text { Sudak Balığı (Sander lucioperca) } \\
\text { Beyşehir Gölü, Mart-Nisan (2010) }\end{array}$ & 2.36 & 2.82 & 2.32 & 1.22 & 12.58 & 1.43 & 2.6 & 9.7 & 9.2 \\
\hline $\begin{array}{l}\text { Tekin-Özan (2008) (yaş ağırlık) } \\
\text { Kadife Balığı (Tinca tinca) } \\
\text { Beyşehir Gölü (2003-2004) }\end{array}$ & & & & & & & $\begin{array}{l}3.26 \\
8.51\end{array}$ & $\begin{array}{c}2.97 \\
11.68\end{array}$ & \\
\hline $\begin{array}{l}\text { Altındağ \& Yigit (2005) (yaş ağırlık) } \\
\text { Sudak Balığı (Lucioperca lucioperca) } \\
\text { Beyşehir Gölü, İlkbahar (2001) }\end{array}$ & $\begin{array}{c}0.62 \\
0.665\end{array}$ & & $\begin{array}{c}0.675 \\
0.68\end{array}$ & & $\begin{array}{l}0.25 \\
0.26\end{array}$ & & & & \\
\hline $\begin{array}{l}\text { Tekin-Özan \& Kır (2008) (kuru ağırlık) } \\
\text { Sazan Balığı (Cyprinus carpio) } \\
\text { Beyşehir Gölü, Mart (2003)-Şubat (2005) }\end{array}$ & & & & & & & $\begin{array}{c}1.46 \\
19.72\end{array}$ & $\begin{array}{c}4.79 \\
13.73\end{array}$ & \\
\hline $\begin{array}{l}\text { Göksu et al (2003) (yaş ağırlık) } \\
\text { Sudak Balığı (Stizostedion lucioperca) } \\
\text { Seyhan Baraj Gölü, Sonbahar-Kış (1998) }\end{array}$ & $\begin{array}{l}0.00 \\
0.55\end{array}$ & & & & & & $\begin{array}{l}1.68 \\
2.24\end{array}$ & $\begin{array}{l}0.41 \\
0.83\end{array}$ & \\
\hline Özyurt et al (2009) (yaş ağırlık) & & & & & & & & & \\
\hline $\begin{array}{l}\text { Sudak Balığı (Sander lucioperca) } \\
\text { Seyhan Baraj Gölü }\end{array}$ & & & & & & 0.13 & & 1.32 & 0.85 \\
\hline Tekin-Özan \& Kır (2007a) (yaş ağırlık) & & & & & & & & & \\
\hline Sudak Balığı (Sander lucioperca) & & & & & & & 5.06 & 4.23 & \\
\hline Kovada Gölü & & & & & & & 23.97 & 8.94 & \\
\hline Mart 2004-Şubat 2005 & & & & & & & & & \\
\hline Mendil et al (2005) (yaş ağırlık) & 0.1 & & 0.9 & 1.6 & 0.7 & 1.0 & 64.3 & 22.6 & 17.3 \\
\hline Tatlı Su Kefali (Leuciscus cephalus) & 0.3 & & 2.1 & 2.3 & 1.6 & 2.0 & 145 & 38.6 & 31 \\
\hline Yayın Balığı (Siluris glanis) & 0.2 & & 1.1 & 1.2 & 0.8 & 1.0 & 96.3 & 22.4 & 22.1 \\
\hline Sazan Balığı (Cyprinus carpio) & 0.2 & & $\begin{array}{l}1.3 \\
0.7\end{array}$ & $\begin{array}{l}1.6 \\
2.0\end{array}$ & $\begin{array}{l}1.3 \\
0.8\end{array}$ & $\begin{array}{l}1.5 \\
1.2\end{array}$ & $\begin{array}{l}107 \\
86.8\end{array}$ & $\begin{array}{l}25.2 \\
17.4\end{array}$ & $\begin{array}{l}28.5 \\
28.6\end{array}$ \\
\hline Siraz Balığı (Capoeta capoeta) & 1.0 & & 1.8 & 3.4 & 1.3 & 2.6 & 150 & 37.1 & 38 \\
\hline Hampinar, Akbelen, Dutluca, Almus, & 0.2 & & 0.8 & 2.4 & 0.6 & 1.8 & 143 & 19.2 & 35.5 \\
\hline Kızık, Uluöz Göletleri, İlkbahar-Yaz (2003) & 1.2 & & 2.4 & 3.4 & 1.5 & 4.1 & 197 & 26.4 & 72.9 \\
\hline Öztürk et al 2009 (yaş ağırlık) & & & & & & & & & \\
\hline Sazan Balığı (Cyprinus carpio) & 0.17 & & 2.14 & 1.27 & 1.18 & 3.85 & 16.55 & & \\
\hline Avsar Baraj Gölü, 2008 & & & & & & & & & \\
\hline Tekin-Özan \& Kır 2007b (yaş ağırlık) & & & & & & & & & \\
\hline Turna Balığı (Esox lucius) & & & & & & & 0.25 & 0.13 & \\
\hline Işıklı Gölü, Aralık 2002- Kasım 2003 & & & & & & & & & \\
\hline Uysal et al 2009 (yaş ağırlık) & 0.16 & TI A & & TI $A$ & 039 & 1.51 & 18.44 & 30.06 & 0.48 \\
\hline Havuz balığı (Carassius carassius) & 43.2 & ILA & & ILA & 0.39 & 503.3 & 242.6 & 1366.3 & 480 \\
\hline İnci balığı (Alburnus alburnus) & 0.05 & TLA & & TLA & TLA & TLA & 24.88 & 21.1 & TLA \\
\hline Enne baraj gölü, Temmuz 2005 & 13.5 & $1 \mathrm{LA}$ & & $1 \mathrm{LA}$ & $1 \mathrm{LA}$ & $1 \mathrm{LA}$ & 327.3 & 959.09 & \\
\hline
\end{tabular}

TLA, tespit limitlerinin altında 
değerleri bulduğumuz Mn sonuçlarına en yakın değerleri göstermektedir.

Sudak kasinda Cd, Co, Pb, Ni, Cr, Cu, Fe, Al, Zn ve $\mathrm{Mn}$ değerlerinin araştırma süresince mevsimsel dağılımları incelendiğinde genel olarak mineral madde miktarlarının bahar mevsimlerinde daha yüksek olduğu, yaz ve kış mevsimlerinde düşük değerlerde görüldüğü tespit edilmiştir. Göksu et al (2003)'un çalışmasında Zn değerlerinin; TekinÖzan \& Kır (2007a)'ın araştırmasında $\mathrm{Fe}$ ve $\mathrm{Zn}$ verilerinin; Mendil et al (2005)'in araştırma verilerinde mevsimsel dağılımın benzer sonuçlar gösterdiği gözlenmiştir.

Çizelge 2'de belirtilen Ulusal ve Uluslararası standartlarda balık kasında bazı ağır metallerin sınır değerleri üzerine yapılan karşılaştırmada; çalışmamızda elde ettiğimiz $\mathrm{Cd}, \mathrm{Ni}, \mathrm{Cr}, \mathrm{Cu}$, $\mathrm{Fe}, \mathrm{Al}, \mathrm{Zn}$, ve $\mathrm{Mn}$ sonuçlarının sınır değerleri aşmadığ1 görülmüştür. Co miktarının bir tek ilkbahar mevsiminde aldığ $0.226 \pm 0.12 \mathrm{mg} \mathrm{kg}{ }^{1}$ sonucu ile IAEA (2003) değerini aştığ 1 , fakat diğer sınır değerlerinin altında kaldığ 1 belirlenmiştir. Araştırmamızda elde edilen $\mathrm{Pb}$ miktarı yönünden yapılan değerlendirmede; FAO/WHO (1989), Çin Gıda Standartları (1999) ve uluslararası bazı değer aralıklarında $0.5 \mathrm{mg} \mathrm{kg}^{-1}$ olarak verilen sınır değerlerin altında kaldığı bulunmuştur (Özparlak et al 2012; Zhang et al 2007; Pan \& Wang 2012). Bunun yanında ilkbahar mevsiminde $0.368 \pm 0.106$ $\mathrm{mg} \mathrm{kg}{ }^{-1}$ olan $\mathrm{Pb}$ değeri $0.3 \mathrm{mg} \mathrm{kg}^{-1}$ olan referans sinır değerlerinin üzerinde olduğu tespit edilmiştir. Yine $\mathrm{Pb}$ miktarının sonbahar mevsiminde ölçülen $0.217 \pm 0.067 \mathrm{mg} \mathrm{kg}^{-1}$ sonucu sinır değeri $0.3 \mathrm{mg} \mathrm{kg}^{-1}$ olan referans değerlerinden düşük, $0.2-0.12 \mathrm{mg} \mathrm{kg}^{-1}$ referans değerlerinden yüksek olduğu görülmüştür. $\mathrm{K}_{1 S ̧}$ mevsiminde elde edilen $0.15 \mathrm{mg} \mathrm{kg}^{-1} \mathrm{~Pb}$ değerinin sınır değerler yönünden sadece IAEA (2003) sınır değerlerini geçtiği belirlenmiştir.

Bazı mineral maddelerin tüketilebilir sınır değerleri Çizelge 1'de verilmiştir. Tüketilebilir sınır değerler ile araştırma sonuçlarımız karşılaştırıldığında; $\mathrm{Co}, \mathrm{Ni}, \mathrm{Cr}, \mathrm{Cu}, \mathrm{Fe}, \mathrm{Al}$ ve $\mathrm{Mn}$ sonuçlarının tüketilebilir limit değerlerini aşmadığı tespit edilmiştir. EPA 2000 ve FAO/WHO-Codex
Stan 193-1995'e göre sınır değerleri aşmayan Cd miktarının ATSDR değerlerine göre yaz, sonbahar ve kış mevsimlerinde belirtilen limit değerlerin üzerine çıktığ 1 belirlenmiştir. $\mathrm{Pb}$ için limit değer sadece FAO/WHO-Codex Stan 193-1995'de belirtilmiştir (Figueira et al 2011). Sadece ilkbahar mevsiminde sudak kasında bulunan $\mathrm{Pb}$ miktarının belirtilen sınır değeri aştığı görülmüştür. Mevsimsel olarak sudak kasında tespit edilen Zn sonuçlarının ATSDR ve Çin Besin Enstitüsü sınır değerlerinin üzerinde bulunduğu, FAO/WHO-Codex Stan 193-1995 limit değerlerinin altında olduğu tespit edilmiştir (hesaplamalar $70 \mathrm{~kg}$ insan ağırlığı değerlerine göre yapılmıştır).

Çalışma sonucunda Pb miktarının limit değerler üzerinde bulunduğu tespit edilmiştir. Yapılan diğer araştırmalarda da $\mathrm{Pb}$ miktarlarının sınır değerlerin üzerinde olduğu görülmektedir. Ulusalveuluslararası sınır değerler yönünden iç su kaynaklarımızın $\mathrm{Pb}$ miktarı yönünden takip edilmesinin ve kirletici faktörlerin önüne geçilmesi gerektiği kanaati hâsıl olmuştur. Yine araştırma süresince tespit edilen $\mathrm{Cd}$, $\mathrm{Pb}$ ve $\mathrm{Zn}$ sonuçlarının uluslararası standartlarca verilen tüketilebilir limit değerlerinin üzerlerinde olduğu görülmüştür. Ağır metal sınıfinda bulunan ve insan beslenmesinde olumlu bir etkisi bulunmayan $\mathrm{Pb}$ ve $\mathrm{Cd}$ miktarlarının sınır değerler ve tüketilebilir limitlerin üzerinde olması insan ve çevre sağlı̆̆ 1 açısından dikkat edilmesi gereken nokta olarak görülmektedir. Çalışma verilerimizde elde ettiğimiz Al sonuçlarına daha önceki literatür araştırmalarında rastlanılmamıştır, bu yönüyle $\mathrm{Al}$ verileri yönünden araştırmamızın bir kaynak oluşturacağı düşünülmektedir.

\section{Kaynaklar}

Alina M, Azrina A, Y. Mohd Yunus A S, Mohd Zakiuddin S, Mohd Izuan Effendi H \& M. Rizal R (2012). Heavy metals (mercury, arsenic, cadmium, plumbum) in selected marine fish and shellfi sh along the Straits of Malacca. International Food Research Journal 19 (1): 135-140

Altındağ A \& Yiğit S (2004). The zooplankton fauna and seasonal distribution Beyşehir Lake. Gazi Eğitim Fakültesi Dergisi 24: 217-225 
Altındağ A \& Yiğit S (2005). Assessment of heavy metal concentrations in the food web of lake Beyşehir, Turkey. Chemosphere 60: 552-556

Atici T, Obali O, Altindag A, Ahiska S \& Aydın D (2010). The accumulation of heavy metals $(\mathrm{Cd}, \mathrm{Pb}, \mathrm{Hg}, \mathrm{Cr})$ and their state in phytoplanktonic algae and zooplanktonic organisms in Beysehir Lake and Mogan Lake, Turkey. African Journal of Biotechnology 9(4): 475-487

ATSDR (2004). Agency for Toxic Substances and Disease Registry, Division of Toxicology ToxFAQs, CAS, 7440-48-4

ATSDR (2013). Agency for Toxic Substances and Disease Registry. U.S. Department of Health and Human Services, Public Health Services. Atlanta, GA 30333: U.S. Available via: http://www.atsdr.cdc.gov/ toxguides/toxguide-2.pdf

Babaoğlu M (2007). Beyşehir Gölü'nün Sorunları ve Alınması Gereken Önlemler. Konya İl Genel Meclisi "Beyşehir Gölü Araştırma Komisyonu" Raporu, s. 1-34

Bernhard M (1976). Manuel of Methods in Aquatic Environment Research. FAO Fisheries Technical Paper No 158 FIRI/T 158, Rome, pp. 123

Chen W D, Zhang M \& Shrestha S (2007). Compositional Characteristics and Nutritional Quality of Chinese Mitten Crab (Eriocheir sinensis). Food Chemistry 103:1343-1349

Codex Standard 193 (1995). Codex General Standard For Contaminants and Toxins in Food and Feed (PTWI). http://www.fao.org/fileadmin/user_upload/ livestockgov/documents/1_CXS_193e.pdf

EC (2001). Commission Regulation (EC) 466/2001. Setting maximum levels for certain contaminants in foodstuffs. Official Journal of the European Communities, pp. 77

EC (2008). Commission Regulation (EC) No 629/2008 of 2 July 2008 amending regulation (EC) No 1881/2006 setting maximum levels for certain contaminants in foodstuffs. Official Journal of the European Union, L173, 0006-0009

EPA (2000). United States Environmental Protection Agency. Guidance for Assessing Chemical Contaminant Data for Use in Fish Advisories, Volume 2 Risk Assesment and Fish Consumption Limits Third Edition.

Ersoy B (2006). Kuzeydoğu Akdeniz (Adana/Karataş) Bölgesinde Avlanma Mevsiminde Tüketilen Balıkların Besin Kompozisyonu ve Ağır Metal
İçerikleri. Doktora tezi, Çukurova Üniversitesi Fen Bilimleri Enstitüsü Su Ürünleri Anabilim Dalı (Basılmamış), Adana

Fakıoglu Ö \& Demir N (2011). Beyşehir Gölü Fitoplankton Biyokütlesinin Mevsimsel ve Yersel Değişimleri. Ekoloji 20(80): 23-32

Figueira E, Lima A, Branco D, Quintino V, Rodrigues A M \& Freitas R (2011). Health concerns of consuming cockles (Cerastoderma edule L.) from a low contaminated coastal system. Environment International 37: 965-972

Göksu M Z L, Çevik F, Fındık Ö \& Sarıhan E (2003). Seyhan Baraj Gölü'ndeki Aynalı Sazan (Cyprinus carpio L., 1758) ve Sudak (Stizostedion lucioperca L., 1758)'larda Fe, Zn, Cd Düzeylerinin Belirlenmesi. E.U Journal of Fisheries \& Aquatic Sciences 20(1-2): 69-74

IAEA (2003). World-Wide İntercomparison Exercise For The Determination of Trace Elements and Methylmercury in Fish Homogenate International Atomic Energy Agency - 407 Report No IAEA/ AL/144 IAEA/MEL/72Kayhan E F (2006). $\mathrm{Su}$ Ürünlerinde Kadmiyumun Biyobirikimi ve Toksisitesi. Ege Üniversitesi Su Ürünleri Dergisi 23(1-2): 215-220

Koçbaş F (2005). Kuzey Ege Kıyılarında Yayılış Gösteren Mytilus galloprovincialis (Lamarck, 1819) ve Ortam Sedimentlerinde Bazı Ağır Metal $(\mathrm{Cu}, \mathrm{Zn}, \mathrm{Pb}$ ve Cd) Dağılımlarının Araştırılması. Doktora Tezi, Celal Bayar Üniversitesi Fen Bilimleri Enstitüsü (Basılmamış), Manisa

Mendil D, Uluozlu O D, Hasdemir E, Tuzen M, Sari H \& Suicmez M (2005). Determination of trace metal levels in seven fish species in lakes in Tokat, Turkey. Food Chemistry 90: 175-179

Mol S (2011). Levels of Heavy Metals in Canned Bonito, Sardines and Mackerel Produced in Turkey. Biological Trace Element Research 143(2): 974-982

NisbetC, Terzi G, Pilgir O \& Sarac N(2010). Determination of Heavy Metal Levels in Fish Samples Collected from the Middle Black Sea. Kafkas Universitesi Veteriner Fakültesi Dergisi 16(1): 119-125

Özden Ö, Ulusoy Ş \& Erkan N (2010). Study on the behavior of the trace metal and macro minerals in Mytilus galloprovincialis as a bioindicator species: the case of Marmara Sea, Turkey. Journal für Verbraucherschutz und Lebensmittelsicherheit 5: 407-412 
Özparlak H, Arslan G \& Arslan E (2012). Determination of Some Metal Levels in Muscle Tissue of Nine Fish Species from Beyşehir Lake, Turkey. Turkish Journal of Fisheries and Aquatic Sciences 12: 761-770

Öztürk M, Özözen G, Minareci O \& Minareci E (2009). Determination of Heavy Metals in Fish, Water and Sediments of Avsar Dam Lake in Turkey. Iranian Journal of Environmental Health Science \& Engineering 6(2): 73-80

Özyurt G, Polat A \& Loker G B (2009). Vitamin and mineral content of pike perch (Sander lucioperca), common carp (Cyprinus carpio) and European catfish (Silurus glanis). Turkish Journal of Veterinary and Animal Sciences 33(4):351-356

Pan K \& Wang W X (2012). Trace metal contamination in estuarine and coastal environments in China. Science of Total Environment 16(3): 421-422

Pazi İ (2011). Assessment of heavy metal contamination in Candarli Gulf Sediment, Eastern Aegean Sea. Environmental Monitoring and Assessment 174:199208

Sarı S \& İnan N (2011), Seydişehir ile Beyşehir'in iklimlerinin karşılaştırılması. Selçuk Üniversitesi Sosyal Bilimler Enstitüsü Dergisi, Konya

Sukender K, Jaspreet S, Sneha D \& Munish G (2012). AAS Estimation of Heavy Metals and Trace Elements in Indian Herbal Cosmetic Preparations. Research Journal of Chemical Sciences 2(3): 46-51

Sümbüloğlu K \& Sümbüloğlu V (2000). Biyoistatistik, Hatiboğlu Yayınları:53, 9. Baskı, Ankara, s. 269

Tarım ve Köyişleri Bakanlığı (2000). Koruma ve Kontrol Genel Müdürlügü, Su Ürünleri Kalite Kontrol El Kitab1, s. 187-198

Tekin-Ozan S \& Kir İ (2007a). Seasonal variation of some heavy metals in pike perch (Sander lucioperca L., 1758) and crucian carp (Carassius carassius L., 1758) from Kovada Lake, Turkey. Fresenius Environmental Bulletin 16: 904-909

Tekin-Özan S \& Kir İ (2007b). Accumulation of some heavy metals in Raphidascaris acus (Bloch, 1779) and its host (Esox lucius L., 1758). Türkiye Parazitoloji Dergisi 31(4): 327-329

Tekin-Özan S (2008). Determination of heavy metal levels in water, sediment and tissues of tench (Tinca tinca L., 1758) from Beyşehir Lake Turkey. Environmental
Monitoring and Assessment 145: 295-302. DOI 10. 1007/s10661-007-0038-z

Tekin-Özan S \& Kir İ (2008). Seasonal variations of heavy metals in some organs of carp (Cyprinus carpio L., 1758) from Beyşehir Lake (Turkey). Environmental Monitoring and Assessment 138: 201-206

TUIK (2012). Turkish Statistical Institute, Fishery Statistics,Ankara,Turkey

Tümgelir L, Çubuk H, Çınar Ş, Özkök R, Küçükkara R, Ceylan M, Erol K G \& Çetinkaya S (2007). Beyşehir Gölü'ndeki Tatlısu Kefali (Leuciscus lepidus Heckel, 1843) Populasyonunun Büyüme Özellikleri. Türk Sucul Yaşam Dergisi 5-8: 200-208

Türk Gıda Kodeksi (2002). G1da Maddelerinde Belirli Bulaşanların Maksimum Seviyelerinin Belirlenmesi Hakkında Tebliğ 23.09.2002-24885 Sayılı Resmi Gazete

Türk Gıda Kodeksi (2011). Gıda, Tarım ve Hayvancılık Bakanlığı Türk Gıda Kodeksi Bulaşanlar Yönetmenliği, 29 Aralık 2011-28157 Sayılı Resmi Gazete

Uysal K \& Atalay M A (2007). DPÜ Göleti'nde Ekstantif Yetiştiriciliği Yapılan Aynalı Sazanların (Cyprinus carpio) Gelişimi ve Ağır Metal Akümülasyon Oranlarının Değerlendirilmesi. Türk Sucul Yaşam Dergisi, Ulusal Su Günleri 2007 Sempozyum Özel Sayısı 5-8: 663-670

Uysal K, Köse E, Bülbül M, Dönmez M, Erdoğan Y, Koyun M, Ömeroğlu Ç \& Özmal F (2009). The comparison of heavy metal accumulation ratios of some fish species in Enne Dame Lake (Kütahya/ Turkey). Environmental Monititoring and Assessmet 157: 355-362

WHO/FAO (1989). National Research Council Recommended Dietary 626 Allowances10th ed. National Academy Press., Washington, DC. USA

Zencir Ö \& Korkmaz A Ş (2004). Beyşehir Gölü Kadife Balıklarının (Tinca tinca L., 1758) Et Verimi ve Vücut Kompozisyonu. Tarım Bilimleri Dergisi 10(4): 474480.

Zhang Z, He L, Li J \& Wu Z B (2007). Analysis Heavy Metals of Muscle and Intestine Tissue in Fish in Banan Section of Chongqing from Three Gorges Reservoir, China. Polish Journal of Environmental Studies 16(6): 949-958 